\title{
Research on the Influences of Credit Constraints \& Occupational Heterogeneity on Women's Participation in Continuing Education
}

\author{
Qin Wang \\ School of Economics \\ Nanjing University of Posts and Telecommunications \\ Nanjing, China
}

\author{
Zimin Wang \\ School of Economics \\ Nanjing University of Posts and Telecommunications \\ Nanjing, China
}

\author{
Dongli Lu \\ Foreign Language School \\ Nanjing Agricultural University \\ Nanjing, China
}

\begin{abstract}
In this paper, the microcosmic data of 'China Family Panel Studies (CFPS)' are used to analyze the impacts of gender, marriage and childbearing, occupational heterogeneity and credit constraints on adults' participation in continuing education. The study finds that both marriage and childbearing have a negative but not remarkable impact on the female labor force's participation in adult continuing education; occupational heterogeneity has a remarkable impact on adults' participation in continuing education; relaxing credit constraints can be conducive for adults' participation in continuing education. From the perspective of control variables, the higher the education level of the labor force, the more willing they'd like to take continuing education; there are more urban labor force to take continuing education when compared to rural labor force, and which region/area (East/Central/West) the labor force are from doesn't have any remarkable impact on their participation in continuing education.
\end{abstract}

Keywords-credit constraint; occupational heterogeneity; adult continuing education

\section{INTRODUCTION}

The positive impact of human capital on economic growth has already been verified by economic theories \& solid evidences. Therefore, all nations attach great importance to the accumulation of human capital. In the new era of economic globalization, innovative technologies springing up, now the labor force are facing a new challenge--- 'lifelong learning'. As an important part of lifelong learning, continuing/further education has played an irreplaceable role and that has been commonly acknowledged by people around the globe. Continuing education \& training for adults have already been taken as important approaches of lifelong learning as early as in 2002 in the <European Report on Quality Indicators of Lifelong Learning $>$ released by EU. The reports to the $16^{\text {th }}, 17^{\text {th }} \&$ $18^{\text {th }}$ national party congresses have requested to establish a learning society and a lifelong education system and also stressed the importance of lifelong learning and development of continuing education. And continuing education and lifelong education have been included in the National Outline for Mid-and-long-term Education Reform and Development (2010-2020) released in July, 2010 for the first time.

Continuing education can update the structure of knowledge, improve occupational competences, reserve human capital and guarantee the labor force's competitive advantages on the labor market. Along with the development of the continuing education industry, the number of people who take continuing education is increasing; however, the gap between the people from different areas (urban or rural), between the people from different regions (East/Central/West), between the people from different communities to take continuing education is still big [1]. As the saying goes: 'women hold up the half sky', as an important part of labor force market, what factors influence the female labor force when deciding to take continuing education for improving the human capital? This question not only concerns the female labor force's occupational competence, but the female labor force's possibility of having a career \& integrating into the society [2] and the potential of economic development.

\section{RESEARCH HYPOTHESES}

According to the Technical \& Vocational Education Terms published by UNESCO, 'continuing education' means the various educations taken by those people who have already been away from normal/regular education and taken a job and can take full responsibilities for whatever they do. In other words, continuing education is a non-academic education, it can meet the need of helping people get a job, improve their professional competences and cultivate their 
tastes in the fields of culture and life. The 'Beijing's Declaration of Establishing a Learning City' issued by Beijing in October, 2013 attaches more importance to the former, that is 'helping public \& private organizations become learning organizations, ensuring that all the employees have a chance to take further education \& training, encouraging employers to support employees to learn at workplaces and providing the young \& adult who want to have a career or have already had a career with a chance to get training. The continuing education for cultivating people's tastes for culture \& life, to a greater extent, means to teach people how to live and consume. Therefore, the continuing education we explain in this article means the former, that is the further education and training the labor force take for meeting the occupational needs. According to human resources development theory, education decisions are influenced by economy, society and personal factors. This article is going to study the factors which impact adults' participation in continuing education from the three perspectives.

\section{A. Marital \& Childbearing Status's Impact on Women's Participation in Continuing Education}

The marital \& childbearing status does impact women's decision on whether or not to take continuing education. In general, people usually think women should take more responsibilities in their families, the society usually has a higher expectation for women than for men in regards to family responsibilities, therefore the professional women who are married and have kids need to raise and educate children; they probably have little time and energy to take further education when compared to men and unmarried women. In contrast, men have a higher expectation for career achievements, and the society and their families have a lower expectation for their direct participation in raising the next generation, so they have more passion, time, energy to take continuing education. For unmarried women, they have no family burden, so they have relatively sufficient time and energy to take further education. We have the hypothesis 1 : there are fewer married women who also have children to take continuing education when compared to men and unmarried women.

\section{B. Occupational Requirements' Impact on Adults' Participation in Continuing Education}

From the perspective of social factors, adults' participation in non-academic continuing education is different from juveniles' participation in the 9-year compulsory education. 'Learning requirements on adults are closely related to the changing role they play in the society. Adults' motivation for learning is from the inside not the outside (M.S.Knowles).' Therefore, the occupational nature of the adult's job influences his/her participation in continuing education. Different occupations have different requirements on the labor force's professional skills and participation in further education. Instance, for the accounting industry, it requires accountants to participate in continuing education and training annually; and constructors must finish the 60-hour continuing education and training in the registered term of validity (a term: 3 years). In order to be qualified, employees are willing to improve their competences and qualities by taking continuing education in various ways. We have the hypothesis 2: different occupational requirements results in adults' different levels of participation in continuing education.

\section{Credit Constraints' Impact on Adults' Participation in Continuing Education}

A large number of documents have researched credit constraints' impact on people's investment in education. The classic theories in regards to human resource investment indicate that if there is no credit constraints, when the internal rate of return (IRR) of investment in education equals to the capitalization rate, then the investment in education will reach the Pareto optimality (Becker, 1962); if facing credit constraints, even if the rate of return brought by education is high, the investment of the low income families that are facing credit constraints in education is below the optimal level (Shultz,1993); poor families' expense on education is low and the educational achievement attained by the children will be small (Becker \& Tomes,1979); family's income level is an important factor that determines the family's expense on education[3]. The aforementioned documents mainly research the family's expense on minor children's education. Although adults are independent in decision making and economy, they are still influenced by credit constraints when deciding whether or not to take continuing education. We have the hypothesis 3: adults with fewer credit constraints take more continuing education.

\section{EMPIRICAL ANALYSES}

\section{A. Model}

The data cited by this research are from the 2014 'China Family Panel Studies (CFPS for short)' newly released by ISSS (Institute of Social Science Survey).

Using the existing research methods in regards to participation behavior and decision in sociology \& economics for reference and on the basis of this article's purpose of research, we adopt the Logistic regression model. The dependent variables of this research are binary variables: the labor force who take continuing education and the labor force who don't take continuing education. Supposing that the possibility of taking continuing education is $\mathrm{P}(\mathrm{Eq} .(1))$.

$$
P=\frac{\left.\operatorname{Exp}\left(\beta_{0}+\beta_{1} X+\beta_{2} \text { CONTROL }+\varepsilon\right]\right)}{1+\operatorname{Exp}\left(\beta_{0}+\beta_{1} X+\beta_{2} \text { CONTROL }+\varepsilon\right)}
$$

In the formula, $\mathrm{X}$ represents the independent variable this article researches, CONTROL represents the control variable, represents the random error. After Logit transferring the Eq.(1), we get the following new Eq.(2):

$$
\mathrm{Z}=\ln \left(\frac{\mathrm{p}}{1-\mathrm{p}}\right)=\beta_{0}+\beta_{1} \mathrm{X}+\beta_{2} \text { CONTROL }+\varepsilon
$$

For the gender factor ('gender'), let's take men as 0 and women as 1 , if the regression coefficient is negative and statistically remarkable, then it means that the female labor force affected by the negative effects when taking further education in comparison with the male labor force. The 
gender factor is used for reflecting if there is a difference between men and women who take continuing education. Relatively speaking, men have a higher target for career achievements than women and the society has a high expectation for males' career success than females. According to the motivation drive theory [4], the stronger the motivation for taking further education to be qualified for a job, the more active in taking further education.

For the childbearing factor ('having child'), let's take the people who have no children as 0 and the people who have children as 1 , if the regression coefficient is negative and statistically remarkable, then it means that having children has a negative impact on the people's participation in continuing education.

For the occupational heterogeneity factor (job class), as per the Occupational Classification System of People's Republic of China released in 2015, occupations can be divided into 8 categories: let's take the unclassified as 0 , the rest categories as $1,2,3,4,5,6$ and 7 , if the regression coefficient is statically remarkable, then it means that occupational heterogeneity influences adults' participation in continuing education, otherwise occupational heterogeneity has no impact on adults' participation in further education.

For the credit constraint factor ('credit'), let's take the population who have credit constraints as 0 and the people who have no credit constraints as 1 , if the regression coefficient is positive and statistically remarkable, then it means that relaxing credit constraints can positively influence adults' participation in continuing education.

The area type reflects the characteristics of the external educational environment that the labor force are in. It's expected that the more the positive factors like more advanced economy, better educational atmosphere in the educational environment, the more beneficial for the labor force's participation in continuing education. The article investigates the area type from two aspects: 1) east, central and west three main areas, 2) city and work, to see economic and educational conditions' joint influences on the labor force's participation in continuing education.

This article takes the west area as 0 , the central area as 1 and the east area as 2 (with taking the west area as the reference) and analyzes the external educational environment's impacts on the people's participation in continuing education.

Taking the rural area(s) the labor force are in as 0 , and the urban area(s) as 1, if the regression efficient is positive, then it means that the external environment of the area has a positive impact on the labor force's participation in continuing education.

In addition, academic educations reflect the levels of education of the labor force. It's assumed that the higher level of education of the labor force, under the further influence of promotion pressure and incentive self-worth, the higher possibility they will take continuing education. This article takes the people with the level of education below elementary school as 0 , the people with the level of junior middle school as 1 , the people with the level of senior middle school/technical secondary school/polytechnic school as 2, the people with the level of junior college as 3 and the people with the level of college/university or above as 4 , if the regression coefficient is positive and statistically remarkable, then it means that the higher the level of education of the labor force, the higher possibility they will take continuing education, and academic education has a positive effect on taking continuing education.

\section{B. Empirical Results}

1) The whole sample: This article does the quantitative analysis to the Logistic model by using the STATA12.0 software, and eliminates the unremarkable variables by using the stepwise regression method.

From the perspective of gender regression result, the regression coefficient is -0.1919 and statically remarkable. The achievement motivation theory[4] indicates that men are more prone to achieving sense of accomplishment via careers. Therefore, relatively speaking, men have a higher possibility to take continuing education than women, women have a lower possibility to take further education.

From the perspective of marriage regression results, although the regression coefficient is negative, it is not statistically remarkable; it means that though marriage has some negative effect on adults' participation in continuing education, the effect is not big. Therefore, marriage doesn't have a big effect on decision-making relates to adults' participation in continuing education.

From the perspective of childbearing regression results, the regression coefficient is -0.3124 and statistically remarkable; it means that having children will cause the labor force to have less time and energy to take continuing education than the ones have no children due to the family responsibility of raising he next generation and the possibility of taking further education will be reduced. Therefore, childbearing has a negative effect on adults' participation in continuing education. "Table I"

From the perspective of occupational categories, the regression coefficient is 0.0565 and statistically remarkable; it indicates that the labor force belong to a specific category is more prone to taking continuing education when compared to the labor force belong to the unclassified category. On the one hand, it is because for the labor force belong to some categories, our nation clearly regulates that they must take further education or training to obtain and keep their occupational qualifications. For instance, the 25 th decree of the Regulations on Professionals' Continuing Education released by Ministry of Human Resources and Social Security in 2015 regulated that the time professionals spend on further education cannot be less than 90 hours per year. On the other hand, it indicates that the occupations can bring the relatively satisfying income and sense of pride, and the labor force are willing to continue their careers through taking further education or training. 
TABLE I. FACTORS THAT INFLUENCES ADULTS’ PARTICIPATION IN CONTINUING EDUCATION

\begin{tabular}{|c|c|c|c|}
\hline Variables & Model 1 & Model 2 & Model 3 \\
\hline Cons & $\begin{array}{l}-3.088 \text { *** } \\
(-26.43)\end{array}$ & $\begin{array}{l}-3.096 * * * \\
(-27.83)\end{array}$ & $\begin{array}{l}-3.1271 * * * \\
(-29.78)\end{array}$ \\
\hline Gender & $\begin{array}{l}-0.1919 * * * \\
(-3.01)\end{array}$ & $\begin{array}{l}-0.1922 * * * \\
(-3.01)\end{array}$ & $\begin{array}{l}-0.1933 * * * \\
(-3.03)\end{array}$ \\
\hline $\begin{array}{c}\text { Childbearing } \\
\text { /Having } \\
\text { Children } \\
\end{array}$ & $\begin{array}{l}-0.3124 * * * \\
(-2.77)\end{array}$ & $\begin{array}{l}-0.3319 * * * \\
(-4.66)\end{array}$ & $\begin{array}{l}-0.3288 * * * \\
(-4.62)\end{array}$ \\
\hline Job Class & $\begin{array}{l}0.0565^{* *} \\
(2.59)\end{array}$ & $\begin{array}{l}0.0565^{* *} \\
(2.59)\end{array}$ & $\begin{array}{l}0.0556^{* * *} \\
(2.55)\end{array}$ \\
\hline Credit & $\begin{array}{l}0.7770 \text { *** } \\
(8.35)\end{array}$ & $\begin{array}{l}0.7776^{* * * *} \\
(8.37)\end{array}$ & $\begin{array}{l}0.7731 \text { *** } \\
(8.33)\end{array}$ \\
\hline Urban/Rural & $\begin{array}{l}0.6138 * * * \\
(9.07)\end{array}$ & $\begin{array}{l}0.6132 * * * \\
(9.07)\end{array}$ & $\begin{array}{l}0.6010 * * * \\
(9.11)\end{array}$ \\
\hline Education & $\begin{array}{l}0.2714 * * * \\
(12.17)\end{array}$ & $\begin{array}{l}0.2712 * * * \\
(12.17)\end{array}$ & $\begin{array}{l}0.2727 * * * \\
(12.26)\end{array}$ \\
\hline $\begin{array}{c}\text { Three Main } \\
\text { Areas }\end{array}$ & $\begin{array}{l}-0.0335 \\
(-0.83)\end{array}$ & $\begin{array}{l}-0.0336 \\
(-0.84)\end{array}$ & \\
\hline Marriage & $\begin{array}{l}-0.0282 \\
(-0.22)\end{array}$ & & \\
\hline
\end{tabular}

From the perspective of credit constraint, the regression coefficient is 0.7770 and statistically remarkable; it indicates that if the labor force have relatively high incomes or can receive the corresponding subsidies if taking further education, then they will have more continuing education. On the contrary, if the labor force are influenced by the credit constraints and need to earn money, then they will be unwilling to give up their current careers and take continuing education. Therefore, if we want to make the labor force take (more) continuing education, then we need to reduce the credit constraints on the workers.

From the perspective of academic education, the regression coefficient is 0.2714 and statistically remarkable; it indicates that the labor force with the higher education levels are more able to well understand the importance of taking further education and they will be more willing to take continuing education. Or the labor force with high educational background often take the professions of high technical natures, taking further education can make them more qualified for the career developments, so they become more willing to take continuing education.

From the perspective of urban/rural areas, the regression coefficient is 0.6138 and statistically remarkable; it indicates that the urban labor force are more willing to take further education when compared to the rural labor force. This is because there are more and better educational resources in urban areas than in rural areas, and others like better transportation \& network, so it's easier for the urban labor force to have continuing education, so they are more willing to do that.

From the perspective of three main areas, the regression coefficient is -0.0335 but not statistically remarkable; it indicates that although the labor force in central \& west areas are negatively influenced by the regional educational environments when taking further education, the influence is not big. Therefore, the different external educational environments among three main areas is not a decisive factor which influences the labor force's decision on whether or not taking further education.

2) The female sample: In this part, the article also does the quantitative analysis to the female population (5458 women) by using the STATA12.0 software \& Logistic model; for regression results, please see "Table II".

TABLE II. FACTORS THAT INFLUENCES WOMEN'S PARTICIPATION IN CONTINUING EDUCATION

\begin{tabular}{|c|l|l|l|l|}
\hline Variables & \multicolumn{1}{|c|}{ Coef. } & Std.Err. & \multicolumn{1}{|c|}{$\mathbf{Z}$} & $\mathbf{P}>\mathbf{Z}$ \\
\hline Cons & $-1.8047 * * *$ & 0.0934 & -19.3200 & 0.0000 \\
\hline Marriage & $-0.1863 *$ & 0.1091 & -1.7100 & 0.0880 \\
\hline $\begin{array}{c}\text { Childbearing/ } \\
\text { Having Child }\end{array}$ & $-0.2070^{* *}$ & 0.0953 & -2.1700 & 0.0300 \\
\hline Job Class & $0.0813 * * *$ & 0.0188 & 4.3200 & 0.0000 \\
\hline Credit & $0.3322^{* * *}$ & 0.0771 & 4.3100 & 0.0000 \\
\hline Education & $0.1314 * * *$ & 0.0176 & 7.4700 & 0.0000 \\
\hline Urban/Rural & $0.4511 * * *$ & 0.0533 & 8.4600 & 0.0000 \\
\hline $\begin{array}{c}\text { Three Main } \\
\text { Areas }\end{array}$ & -0.0324 & 0.0316 & -1.0200 & 0.3070 \\
\hline
\end{tabular}

From the regression result of marital status, the regression result of the female population differ from the one of the whole population, marriage has a negative impact on women's participation in continuing education and it is statistically remarkable; it indicates that the possibility of women taking further education to improve their professional competences \& life qualities reduces after marriage.

From the perspective of childbearing/having child, for the female population, the regression coefficient (childbearing influences women's participation in continuing education) is -0.2070 and statistically remarkable; it indicates that after the childbearing, women have to take more responsibilities for raising children and doing housework, so they will have a low possibility to take further education. In other words, for the female labor force who have no children, they have no children to raise, so they have more time and energy to take further education. Therefore, when encouraging women to take further education, we should set the more flexible time and locations for the married women with children.

From the perspective of occupational categories, for the female population, the regression coefficient is 0.0813 and statistically remarkable, it's consistent with (the regression coefficient of) the whole population; it indicates that for women, except for the unclassified category that is restrained by the rules \& regulations of occupational education industry association, in order to be always qualified for the occupations, they will still choose to take continuing education. Therefore, the rules \& regulations of relevant industries have some binding effects for both the ordinary labor force and the female labor force.

From the perspective of credit constraint, (for the female labor force who take continuing education) the regression coefficient is 0.3322 and statistically remarkable, it's consistent with (the regression coefficient of) the whole population; it indicates that if the female labor force have the relatively high incomes or can get the corresponding 
subsidies if they take continuing education, then the possibility of they taking further education will be increased. This indicates the credit constraint is still an important factor that restrains the female labor force from taking further education.

From the perspective of academic education, (for the female labor force who take continuing education) the regression coefficient is 0.1314 and statistically remarkable, it's consistent with (the regression coefficient of) the whole population; it indicates that the higher degree the female labor force have, the more willing they'd like to take continuing education. This is closely related to the in-charge awareness \& occupation competences of the labor force who have high degrees, because they are more possible to take the careers with high technical requirements.

From the perspective of urban/rural areas, the regression result of the female population is consistent with (the regression result of) the whole population, the regression coefficient is positive and statistically remarkable; it indicates that the urban female labor force have a higher possibility than the rural female labor force to take continuing education. This is closely related to the accessibility to continuing educations in cities.

From the perspective of three main areas, the regression result of the female population is consistent with (the regression result of) the whole population, the regression coefficient is negative and not statistically remarkable; it indicates that there is no fundamental difference between the female labor force in central \& west areas and the female labor force in the east area in taking further education. There is no regional difference for the female labor force who take continuing education.

\section{CONCLUSION}

On the basis of lifelong learning, this article analyzes the factors that influence adults' \& women's participation in continuing education from the perspectives of gender, marital \& childbearing status, occupational categories, credit constraint, level of education, urban \& rural areas and three main areas (West, Central and East). The empirical results indicate that gender has some impact on adults' participation in continuing education, men have a higher possibility to take continuing education when compared to women; no matter for adults or women, childbearing/having child has some negative influence on their participation in continuing education; occupational heterogeneity has some remarkable impact on adults' participation in continuing education; relaxing credit constraint can be helpful for adults' participation in continuing education; the higher the level of education of the labor force, the more willing they'd like to take continuing education; the urban labor force are more prone to taking further education when compared to the rural labor force; but the difference among the labor forces' (from the three main regions) participation in continuing educations is not remarkable; marriage has some remarkable negative impact on women's participation in continuing education, although it has some negative impact on the whole population, the impact is not statistically remarkable.
According to the conclusions of the empirical analyses, the article makes the following suggestions:

First, develop long-distance education by using flexible and diverse teaching methods. For the adult labor force, taking further education means they need to work while taking care of their families; especially for the female labor force, having the intensive face-to-face education can be influenced by many constraints. Along with the popularization of cellphone and the development of mobile internet technology, the long-distance education becomes convenient and efficient and allows people to take education any place any time. Therefore, we should actively promote the long-distance education in the field of continuing education.

Second, add learning content to continuing education and encourage developing education resources for women. For the characteristic that married women's participation in continuing education or training reduces along with the marriage, we can specifically develop some 'life quality' training relates to women's lives. Because some women have to shoulder the responsibility of taking care of their families after marriage, and general training on the market cannot meet their demands, so they reduce the participation in continuing education. Therefore, we can learn from the methods implemented by some developed nations like Japan, establish non-profit education or training course relates to homemaking services and encourages the female labor force to participate.

Third, establish investment funds for further education and support developing continuing education. Increasing investment in public institutes for continuing education, providing subsidies like 'training coupon' for the groups with financial troubles like the low-income or jobless people, giving opportunities of taking further education to adults who're facing credit constraint. In addition, the corresponding subsides and financial support can be provided to the labor force who take further education/training and the training institutes which provide further education/training respectively, or give the enterprises that the labor force work for some preferential policies.

Fourth, further improve the relevant norms relate to continuing professional education. (To be more specific,) improve relevant professional norms from the point of the industry association, specify the interested parties' responsibilities and obligations in continuing education, and enhance the supervision over the execution of continuing education; implement the profession admittance regulations, formulate regulations relate to employees' (especially professionals) participation in continuing education, and regulate employers to provide the corresponding guarantees like the 'paid continuing education' policy to the employees who take continuing education.

Fifth, encourage people to take high academic educations. We can learn from the empirical analyses that the higher level of education of the labor force, the more willing they'd like to take continuing education; so all the governments and education authorities should establish the corresponding 
policies to encourage the labor force to finish academic educations, in particular the compulsory education; and develop secondary vocational education and technical education on that basis.

Sixth, increase the investment in rural areas' education resources, in particular the investment in infrastructure like broadcast, TV and network and let the rural labor force have more access to continuing education resources; and this can be helpful for increasing their possibility of taking continuing education.

The CPFS micro data used by this article are not very sufficient due to the lack of the data relate to the respondents' specific occupations and whether the continuing education/training they take matches with the occupations or not. Therefore, the empirical part still needs to be further researched $\&$ improved by more research data.

\section{REFERENCES}

[1] Han Min, Hao Keming. Equity of Training \& Continuing Education against the Background of Lifelong Learning \& Its Policy Research [J], 2007(7), Page 2 10.

[2] Wang Rui, Factors that Influence Adults' Participation in Continuing Education: from the Perspective of the Labor Force Market Structure [J], China Adult Education, 2013(4), Page 64 69.

[3] Chen Yongwei, Gu Jiafeng \& Shi Yupeng, Housing Wealth, Credit Constrains and Urban Families' Expenses on Educations----Proofs from the CFPS2010 Data [J], 2014 (1), Page 89 101.

[4] Wang Xuesong \& Liu MingChao, Brief Introduction about the Achievement Motivation Theory [J], Co-operative Economy \& Science, 2008 (11), Page 37 38.

[5] Jiang Lianqiong, Lu Taihong \& Zhou Lu, Consumers' Gift Purchase Decision: Relation-oriented or Motivation-driven [J], Journal Of Sun Yat-sen University (Social Science Edition), 2007 (5), Page 117 123 $\& 128$. 